\title{
Technological Nonviolence and Girls Creating a Counter Discourse
}

\author{
Claudia Mitchell
}

\section{$\cos 80$}

The idea of devoting a special issue of Girlhood Studies to what Jonathan Bock (2012) calls technologies of nonviolence comes at a critical time in girlhood studies. On the one hand, technology-especially digital technology — and various social media platforms are firmly entrenched in the everyday lives of many young people around the world. On the other, questions regarding who has access to technology and how technology is used and abused continue to dominate the fields of girlhood studies in particular and of youth studies more broadly. Nowhere is this more evident than in relation to violence and social media in the lives of girls and young women. The many movements and organizations_-some of them, like Take Back the Tech, ${ }^{1}$ global in scope — are playing a key role in contributing to altering the landscape.

The notion of technologies of nonviolence offers a frame, as it were, in which to set the various approaches, interventions, movements, and personal experiences that see technology as something that can be central to creating a counter discourse rather than one that is only about threat and danger. While this idea has been explored in the many versions of a topic that may be defined as "Social Media: Friend or Foe?" over the years, it is clearly one that is not going to disappear. The questions raised in this special issue explore this framing in a variety of ways that range from offering close readings of the vlogs of girls and young women in relation to rape culture through to a careful consideration of the legal implications of online violence, and from seeing the emancipatory potential in areas such as disability studies to the promotion of STEM (science, technology, engineering, and mathematics) for girls. At the same time, as several authors explore, there is still a great deal of work to be done, particularly in the context of sex trafficking but even (or especially) in approaches that explicitly seek to be non- 
violent. The very tools of technology used, for example, in participatory visual research may bring with them new expressions of violence.

The inspiration and administrative support for this special issue comes out of a six-year partnership study, Networks for Change and Well-being: Girl-led "from the Ground Up" Policy Making to Address Sexual Violence in Work with Indigenous Girls in Canada and South Africa. ${ }^{2}$ One key component of that study, headed up by the Working Group on Communication and Social Action, is organized through the Technologies of Nonviolence Digital and Social Media Space of the Participatory Cultures Lab at McGill University. I am very grateful to Laurel Hart for taking on the guest editorship of this special issue and also acknowledge the scope of her own research in the area of girls, women, and technology ranging from her award-winning doctoral dissertation (Hart 2016) to her involvement in the Participatory Cultures Lab and in the Networks for Change and Well-being study.

\section{Acknowledgments}

This special issue was supported through a grant from the Social Sciences and Humanities Research Council of Canada (SSHRC) (award number 895-2013-3007) and a grant from the International Development Research Centre (IDRC) (award number 107777-001).

\section{Notes}

1. www.takebackthetech.net

2. www.networks4change.ca

\section{References}

Bock, Jonathan. 2012. The Technology of Nonviolence: Social Media and Violence Prevention. Cambridge, MA: MIT Press.

Hart, Laurel Marie. 2016. “Her Mind's Eye: Women's Visions of Urban Life Explored in a Place-Based Social Mobile Photography Community Online and On the Ground." PhD diss., Concordia University. 